diseases in Turkey by law. We aimed to evaluate proportion of pneumoconiosis in occupational diseases and occupational pulmonary diseases in annual statistics reports of SSI.

Methods Annual statistics reports published between 20062015 by SSI were evaluated. Diagnoses classified as pneumoconiosis in reports published before 2013 were coal worker's pneumoconiosis, asbestos or other mineral fibre induced pneumoconiosis, talcosis, silicosis, aluminosis, boxide fibrosis, beriliosis, graphite fibrosis, siderosis, stannosis, and other unclassified pneumoconiosis. Diagnoses classified as pneumoconiosis in reports published starting from 2013 were silicosis and silicotuberculosis, asbestosis, silicatosis, siderosis, and pneumoconiosis induced by hard metal dusts, aluminium, and its compounds.

Result Total numbers of cases with occupational diseases varied between 351 and 1208 in annual reports of SSI. Most frequent occupational diseases were pneumoconiosis and diseases induced by lead and its dusts. When occupational diseases listed according to the frequency, rank of pneumoconiosis was 1 or 2 in all of the evaluated years. Total numbers of cases with pneumoconiosis varied between 68-1010. Percentage of pneumoconiosis in all cases with occupational diseases and in cases with occupational pulmonary diseases varied between $19.3 \%-83.6 \%$ and $80.2 \%-99.3 \%$ respectively.

Discussion Despite low total numbers of occupational diseases in the annual SSI statistics, pneumoconiosis constitutes the major proportion of occupational diseases in Turkey. This could be a result of directive about dust induced diseases which defines periodical health surveillance for workers with high-risk occupations. Proper application of initial assessment of fitness and health surveillance for workers with current or prior history of risk of pneumoconiosis may increase diagnoses.

\section{EVALUATION OF THE RELATIONSHIP BETWEEN SMOKING AND PNEUMOCONIOSIS: A REVIEW OF THE LITERATURE}

${ }^{1}$ Seval Müzeyyen Ecin*, ${ }^{1}$ Adem Koyuncu, ${ }^{1}$ Abdulsamet Sandal, ${ }^{2}$ Ali Naci Yildiz. ${ }^{1}$ Hacettepe University, Faculty of Medicine, Department of Internal Medicine, Unit of Occupational Medicine, Ankara, Turkey; ${ }^{2}$ Hacettepe University, Faculty of Medicine, Department of Public Health, Ankara, Turkey

\subsection{6/oemed-2018-ICOHabstracts.1104}

Introduction Pneumoconiosis is a condition that results in fibrosis in the lung tissue due to accumulation of inorganic dusts in the lung. Smoking and exposure to inorganic dusts affect respiratory functions separately. However, the combined effect may be much more increased than either exposure alone. In this review, we aimed to evaluate the relationship between smoking and dust exposure and their effects on pulmonary function tests (PFT).

Methods Studies have been conducted between 1961 and 2016 on the relationship between smoking and dust exposure, and their effects on PFT were evaluated.

Result All 4 researches evaluated were performed in coal workers. In 1961, Ashford, et al evaluated 4014 coal workers in 3 coal mines of Scotland. Statistically significant increase in respiratory symptom frequency and decrease in forced expiratory volume in $1 \mathrm{~s}$ (FEV1) were found in smokers compared to non-smokers. In 1980, Oger, et al investigated 465 coal workers with diagnosis of pneumoconiosis. Airflow obstruction was detected in $74.1 \%$ of smokers and $26.3 \%$ of non- smokers. In 1988, William, et al included 3380 coal workers to their study in the United Kingdom and found that smokers had higher respiratory symptoms and more FEV1 reductions. In China, Quink, et al included 376 coal workers to their study published in 2016. Of those, 200 (53.1\%) were smokers. Cigarette smoking and exposure to dust impaired respiratory functions more than exposure alone and it has been determined that as the exposure time increases, the abnormality increases in the PFT. No significant difference was found between the non-smoking coal workers and the non-smoking control group.

Discussion Results of researches supporting combined effects of smoking and dust exposure reveal the requirement of minimization of dust exposure and cessation of smoking. Further studies could be performed to elucidate relationship between smoking and other types of dust exposures in terms of respiratory symptoms and dust exposure.

\section{TRENDS IN OCCUPATIONAL DISEASES IN FINLAND 1975-2013}

${ }^{1}$ Riitta Sauni*, ${ }^{2}$ Panu Oksa, ${ }^{3}$ Nina Talola, ${ }^{2}$ Simo Virtanen, ${ }^{3}$ Jaakko Nevalainen, 2,3 Jukka Uitti. 'Department for Occupational Safety and Health, Ministry of Social Affairs and Health, Finland; ' ${ }^{2}$ Finnish Institute of Occupational Health, Tampere/Helsinki, Finland; ${ }^{3}$ University of Tampere, Tampere, Finland

\subsection{6/oemed-2018-ICOHabstracts.1105}

Introduction The objective was to investigate trends in the incidence of recognised and suspected cases of occupational diseases in Finland 1975-2013, including variations by gender and industry.

Methods The data consisted of recognised and suspected cases of occupational diseases registered in the Finnish Registry of Occupational Diseases (FROD) in 1975-2013. From the annual workforce statistics and data of FROD we calculated the incidence of occupational diseases and suspected occupational diseases per 10000 employed. For time trends by industrial sector, we used a five-year moving average and Poisson's regression analysis.

Results Annual average rates of occupational diseases (per 10000 employees) have varied from year to year. The total number was 25.0/10,000 in 1975 and 20.1/10,000 in 2013. Screening campaigns and legislative changes have caused temporary increases.

The highest incidence rates in different industrial sectors were in mining and quarrying $(9.87 ; 95 \% \mathrm{CI}: 8.65$ to 11.30$)$, construction $(9.11 ; 95 \% \mathrm{CI}$ : 9.98 to 10.43$)$, manufacturing (9.04; 95\% CI: 7.93 to 10.36$)$ and in agriculture (8.78; 95\% CI: 7.69 to 10.06 ), when financial sector was the reference (1.0). During that time, women had significantly less occupational diseases than men (RR $0.62 ; 95 \% \mathrm{CI}$ : 0.57 to 0.68).

There is a more distinct decreasing trend from 2005 onwards: the average annual change in incidence was e.g. in agriculture $-9.2 \%$, in transportation $-10.3 \%$ and in construction $-4.7 \%$. The average annual decline was greatest in upper limb strain injuries $(-11.1 \%)$.

Discussion This study provides a useful overview of the status of occupational diseases in Finland over several decades. These data are a valuable resource for investigating which occupations are at an increased risk and where the preventive actions should be focused on. It is important to study the long-term 